\title{
ESOPHAGEAL NEOPLASMS - A SINGLE INSTITUTION REPORT
}

\author{
George Stoyanov ${ }^{1}$, Deyan Dzhenkov ${ }^{2}$, Diana Gancheva ${ }^{3}$ \\ ${ }^{1}$ Student, Faculty of Medicine, Medical University of Varna \\ ${ }^{2}$ Department of General and Clinical Pathology, Forensic Medicine and Deontology, \\ Faculty of Medicine, Medical University of Varna \\ ${ }^{3}$ Department of Internal Medicine, Division of Gastroenterology, \\ Hepatology and Nutrition, Faculty of Medicine, Medical University of Varna
}

\begin{abstract}
INTRODUCTION: Esophageal malignancies are a diverse group of neoplastic processes. The different entries that contribute to the group have a very wide margin of incidence across different populations, attributed to the presence of different predisposing factors. The aim of this study was to establish the statistical prevalence of histologically verified esophageal neoplasms in a single medical institution.
\end{abstract}

MATERIALS AND METHODS: All histologically confirmed cases of malignancies isolated from the esophagus, for a period of three and a half years, registered in the St. Marina University Hospital, Varna, Bulgaria, were retrieved from the pathological archive and their incidence compared in a descriptive statistical manner. The cases were further classified based on their type and age and gender of the patients.

RESULTS: For the set time period, 33 cases $(n=33)$ of esophageal malignancies were registered. From these cases $66.67 \%(n=22)$ were diagnosed as squamous cell carcinoma of the esophagus (SCCE), 30.30\% $(n=10)$ as adenocarcinoma of the esophagus (ACE), and 3.03\% $(n=1)$ - as a non-Hodgkin B MALT lymphoma diagnosis in an 84-year-old male patient. The mean age of diagnosis of patients with SCCE $(n=22)$ was 59.45 years of age, with a standard deviation of \pm 11.05 years, while the mean age of diagnosis of patients with ACE $(n=10)$ was 70.40 years of age, with a standard deviation of \pm 14.83 years.

CONCLUSION: The results show clear statistical difference in the mean age of diagnosis. The male-to-female ratio of all cases is comparable to that of the global population, while the statistical segregation between entries shows a tendency towards that of the developed countries.

Keywords: esophageal malignancies, esophageal squamous cell carcinoma, esophageal adenocarcinoma, retrospective descriptive statistical analysis, oncology

Address for correspondence:

George Stoyanov

Department of Anatomy, Histology and Embryology

Faculty of Medicine

Medical University of Varna

55 Marin Drinov St.

9002 Varna

e-mail: georgi.geesh@gmail.com

Received: May 18, 2016

Accepted: July 19, 2016

\section{INTRODUCTION}

Esophageal neoplasms are a diverse group of neoplastic processes originating from the structures of the esophagus. Epidemiologically the most common entry in this group is the squamous cell carcinoma of the esophagus (SCCE), originating from the striated non-keratinizing epithelial lining of the esophagus (1). SCCE can originate in many loci of the esophagus, but its most common loci are the mid- 
dle and upper third of the esophagus, although it can originate in the lower third, paradoxically, even in the presence of Barret's esophagus in gastro-esophageal reflux disease (GERD) (1).

Adenocarcinoma of the esophagus (ACE) on the other hand originates by means of columnar cell metaplasia on the background of Barrett's esophagus, due to GERD, in the lower third of the esophagus (1). Some other rare entries such as mucosa-associated lymphoid tissue (MALT) lymphomas and stromal tumors are also registered in the esophagus (1).

From an epidemiological standpoint, no other malignant group has such geographical differences when compared to esophageal neoplasms, with more than $500 \%$ difference in incidence between different populations (2-7). The incidence of SCCE is high in developing countries where the incidence can reach up to 700 cases per 100000 capita, nearly $50 \%$ of all registered neoplasms, an average age of onset of 45 years of age and a male-to-female ratio of 2:1 to 2.5:1 (2-7). ACE on the other hand has the highest incidence in developed countries, where it is most highly associated with long-lasting GERD in the elderly population (2-7).

Although most risk factors for these malignancies are well known and their synergic effects on the development of these neoplasms are well researched, there are still a lot of unestablished predisposing factors, as just the presence of the known factors cannot explain the wide margin in incidence (1-2,7-18). Although remaining relatively unchanged, the per capita incidence of esophageal neoplasms is a good indicator for the medical advancements in the field, on the background of the total rise of neoplastic entries in the global population.

The prognosis of patients with diagnosed esophageal malignancies is poor and has historically remained nearly unchanged, with five-year survival for early diagnosed lesion being around 75\%, but with late diagnosis dropping to about 20\% (1-2,19-21).

Screening, early diagnosis and limitation of the risk factors remain the key parts in the medical strategies for these neoplastic entries as they show few symptoms in the early stages and their treatment requires highly trained specialists and costly medical equipment (19-21). It remains to be seen if immuno- prophylaxis against the known predisposing factor of human papillomavirus infection will, in the future, further decrease the incidence of SCCE (14).

\section{MATERIALS AND METHODS}

All histologically confirmed cases of esophageal malignant lesions were retrieved from the central pathological archive of a single medical institution - St. Marina University Hospital, Varna, Bulgaria, for a period of three and a half years (September, 2012 - April, 2016) and their incidence compared by main histological type, age of diagnosis and patient gender. A case was considered as a patient diagnosed with a malignant lesion in the esophagus, histologically verified in the St. Marina University Hospital, Varna, Bulgaria, and not an individual finding in the esophagus diagnosed in the institution. This avoided the statistical blurring from patients biopsied on more than one occasion in the set timeframe, or treated in more than one medical department.

Due to the histological verification criteria in the St. Marina University Hospital, Varna, Bulgaria, patients treated in the structures of the Hospital, but diagnosed in other medical institutions, were excluded from the statistical analysis.

The statistical analysis and graphical representations of the collected data were processed with the MaxStat Pro version 3.6 statistical software engine.

\section{RESULTS}

The total number of patients diagnosed with esophageal malignancies during the three-and-ahalf-year period was $33(n=33)$. From these cases, $66.67 \%(n=22)$ were diagnosed with SCCE, $30.30 \%$ $(\mathrm{n}=10)$ - with ACE, and 3.03\% (n=1) - with a nonHodgkin B MALT lymphoma (Fig. 1).

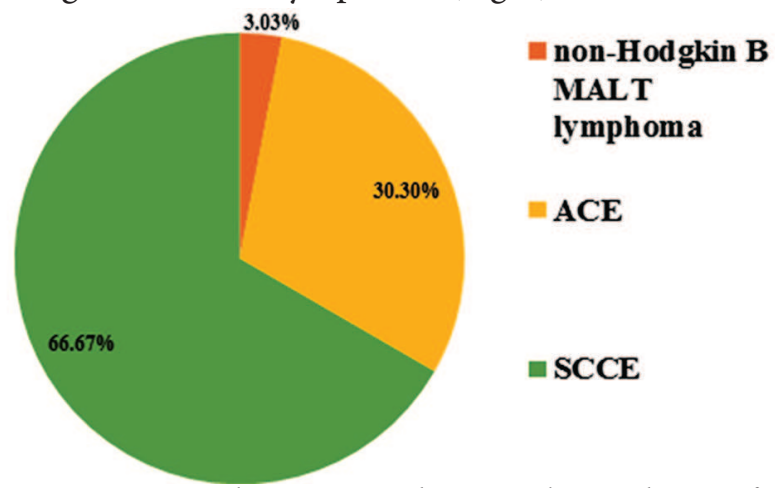

Fig. 1. Statistical comparison between the incidences of histologically confirmed esophageal malignancies 
Analysis of the gender of the patients revealed that the male-to-female ratio of patients with SCCE $(n=22)$ was $16: 6$ or $2.67: 1$, and that of patients with $\operatorname{ACE}(n=10)$ 7:3 or $2.33: 1$ (Fig. 2).

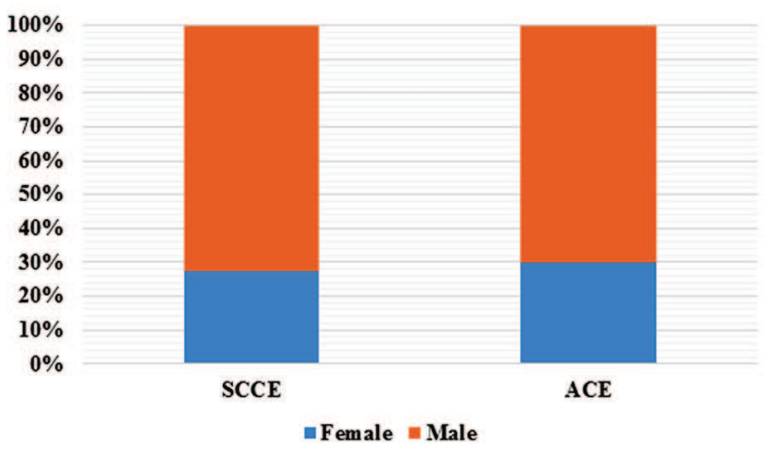

Fig. 2. Male-to-female ratio of the incidence of the two most commonly diagnosed esophageal malignancies SCCE and ACE

The mean age of diagnosis of patients with SCCE $(n=22)$ was 59.45 years of age, with a standard deviation of \pm 11.05 years, while the mean age of diagnosis of patients with ACE $(n=10)$ was 70.40 years of age, with a standard deviation of \pm 14.83 years (Fig. 3 ). The results show a clear statistical difference in the mean age of diagnosis, with SCCE developing mainly at a relatively early age for malignant conditions.

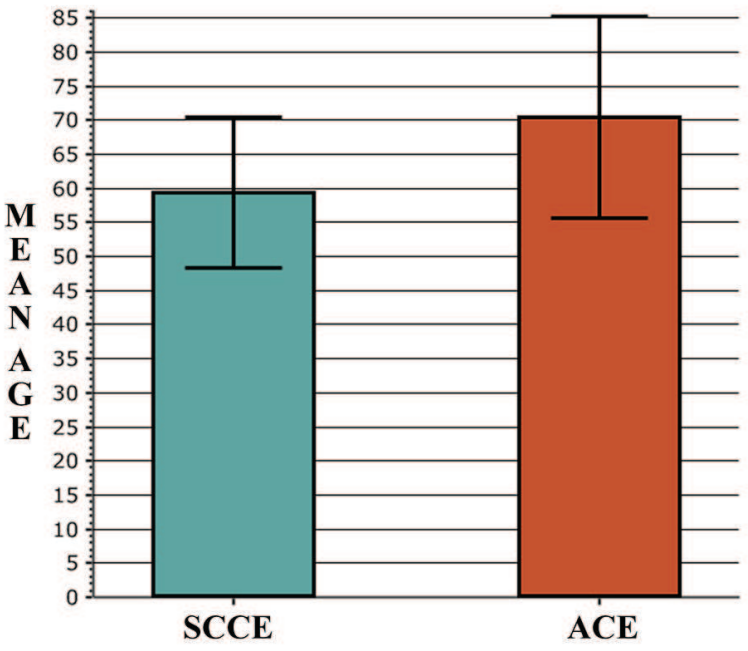

Fig. 3. Mean age of diagnosis of the two most commonly diagnosed esophageal malignancies - SCCE and ACE
The case not shown as part of the statistical analysis of male-to-female ratio and mean age of diagnosis was the case of a non-Hodgkin B MALT lymphoma $(\mathrm{n}=1)$, diagnosed in an 84-year-old male patient.

Only one of the cases $(\mathrm{n}=1)$ was diagnosed as carcinoma in situ, while the other cases $(\mathrm{n}=31)$ were diagnosed as invasive carcinoma, with the exception of the non-Hodgkin B MALT lymphoma $(n=1)$, due to the different mechanisms of its evolution and dissemination, when compared to the epithelial neoplasms ( $\mathrm{n}=32)$.

Cases diagnosed from September 1, 2012 to December 31, $2012(n=5)$ consisted of SCCE $(n=4)$ and ACE $(n=1)$. Cases diagnosed from January 1, 2013 to December 31, $2013(n=8)$ consisted of SCCE $(n=5)$, ACE $(n=2)$ and non-Hodgkin B MALT lymphoma $(\mathrm{n}=1)$. Cases registered from January 1, 2014 to December 31, $2014(n=9)$ consisted of SCCE $(n=6)$ and $\operatorname{ACE}(n=3)$. Cases registered from January 1, 2015 to December 31, $2015(n=8)$ consisted of SCCE $(n=6)$ and ACE $(\mathrm{n}=2)$. Cases registered from January 1 , 2016 to April 30, $2016(n=3)$ consisted of SCCE $(n=1)$ and ACE $(n=2)$. The yearly distribution of all cases $(n=33)$ and their respective histological types is shown on Fig. 4.

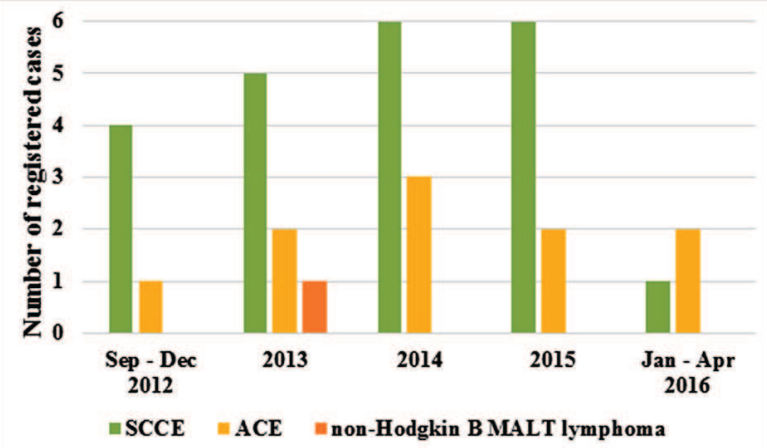

Fig. 4. Yearly distribution of all diagnosed cases of esophageal malignancies according to their histological type

All biopsy samples from ACE cases $(n=10)$ were isolated from lesions in the lower third of the esophagus, while the samples from the SCCE cases $(n=22)$ were isolated from lesions found in the middle and upper third of the esophagus. The biopsy sample from the non-Hodgkin B MALT lymphoma $(n=1)$ 
was isolated from a lesion in the middle third of the esophagus.

\section{DISCUSSION}

The presented results demonstrate a statistical correlation between SCCE and ACE, which is closer to that of developed countries than to that of developing ones and highly representative of the rates of incidence in other Eastern European countries when compared to Wester European ones (2-7,22-26). The male-to-female ratio, on the other hand, is comparable to that of the global population (2-7,22-26).

The reported results are also representative on a national level as seen by the incidence of esophageal malignance in Bulgaria reported in the "Cancer Incidence in Bulgaria, 2013" national oncological report, where esophageal malignancies are reported as $0.7 \%$ of all newly registered oncological entries, with 221 newly registered cases of esophageal malignancies that year and a male-to-female ratio of 3.7:1, higher than the currently reported ratio (27).

Compared to previously reported results of esophageal malignancies diagnosed only in the Clinic of Gastroenterology, Hepatology and Nutrition of the same medical institution in 2007, the currently reported results show a nearly identical male-to-female ratio across all diagnosed cases (28). However, the comparison between the two studies shows an increase of the total percentage of ACE, when compared to SCCE, a characteristic shift, mainly due to the improvement of living standards and medical care, as already reported in other countries (23).

With the spread of the main risk factors across the Bulgarian population and the steady yearly rate of diagnosed cases, the results seem to be of statistical importance (28).

\section{CONCLUSION}

The statistical report seems to be comparable to reports carried out in different populations and the reported figures are closer to those reported in developed countries, with high similarity to other Eastern European countries (2-7,22-28). Despite being relatively rare oncological entries, malignant lesions of the esophagus are hard to diagnose in the early stages of their development and require highly trained medical personnel and costly medical equipment to be treated, with the five-year survival rate being rel- atively low (1-2,19-21,27). Prevention, restriction of the risk factors, medical screening, early diagnosis and treatment are key factors in the medical strategies for treating these rare malignant entries, commonly diagnosed in young individuals of working age $(19-21,28)$.

\section{ACKNOWLEDGEMENTS}

The authors would like to thank the reviewers of Scripta Scientifica Medica for their comments and recommendations, which represent an important contribution of the final form of this article.

\section{REFERENCES}

1. Robbins and Cotran. Pathologic Basis of Disease. $9^{\text {th }}$ edition. Elsevier Saunders, Philadelphia; 2015

2. Messmann H. Squamous cell cancer of the oesophagus. Best Pract Res Clin Gastroenterol. 2001;15(2):249-65.

3. Kachala R. Systematic review: epidemiology of oesophageal cancer in Sub-Saharan Africa. Malawi Med J 2010;22(3):65-70.

4. Zhang HZ, Jin GF, Shen HB. Epidemiologic differences in esophageal cancer between Asian and Western populations. Chin J Cancer 2012;31(6):281-6.

5. Zhang Y. Epidemiology of esophageal cancer. World J Gastroenterol 2013;19(34):5598-606.

6. Napier KJ, Scheerer M, Misra S. Esophageal cancer: A Review of epidemiology, pathogenesis, staging workup and treatment modalities. World J Gastrointest Oncol 2014;6(5):112-20.

7. Arnold M, Soerjomataram I, Ferlay J, Forman D. Global incidence of oesophageal cancer by histological subtype in 2012. Gut. 2015;64(3):381-7.

8. Sun L, Yu S. Meta-analysis: non-steroidal anti-inflammatory drug use and the risk of esophageal squamous cell carcinoma. Dis Esophagus 2011;24(8):544-9.

9. Hardefeldt HA, Cox MR, Eslick GD. Association between human papillomavirus (HPV) and oesophageal squamous cell carcinoma: a meta-analysis. Epidemiol Infect 2014;142(6):1119-37.

10. Petrick JL, Wyss AB, Butler AM, Cummings $C$, Sun X, Poole C, Smith JS, Olshan AF. Prevalence of human papillomavirus among oesophageal squamous cell carcinoma cases: systematic review and meta-analysis. Br J Cancer 2014;110(9):2369-77. 
George Stoyanov, Deyan Dzhenkov, Diana Gancheva

11. Li X, Gao C, Yang Y, Zhou F, Li M, Jin Q, Gao L. Systematic review with meta-analysis: the association between human papillomavirus infection and oesophageal cancer. Aliment Pharmacol Ther 2014;39(3):270-81.

12. Liyanage SS, Rahman B, Gao Z, Zheng Y, Ridda I, Moa A, Newall AT, Seale H, Li Q, Liu JF, Macintyre CR. Evidence for the aetiology of human papillomavirus in oesophageal squamous cell carcinoma in the Chinese population: a meta-analysis. BMJ Open 2013;3(11):e003604.

13. Liyanage SS, Rahman B, Ridda I, Newall AT, Tabrizi SN, Garland SM, Segelov E, Seale H, Crowe PJ, Moa A, Macintyre CR. The aetiological role of human papillomavirus in oesophageal squamous cell carcinoma: a meta-analysis. PLoS One 2013;8(7):e69238.

14. Mork J, Lie AK, Glattre E, Hallmans G, Jellum E, Koskela P, Møller B, Pukkala E, Schiller JT, Youngman L, Lehtinen M, Dillner J. Human papillomavirus infection as a risk factor for squamous-cell carcinoma of the head and neck. N Engl J Med 2001;344(15):1125-31.

15. Syrjänen K. Geographic origin is a significant determinant of human papillomavirus prevalence in oesophageal squamous cell carcinoma: systematic review and meta-analysis. Scand J Infect Dis 2013;45(1):1-18.

16. Sitas F, Egger S, Urban MI, Taylor PR, Abnet CC, Boffetta P, O'Connell DL, Whiteman DC, Brennan P, Malekzadeh R, Pawlita M, Dawsey SM, Waterboer T. InterSCOPE study: Associations between esophageal squamous cell carcinoma and human papillomavirus serological markers. J Natl Cancer Inst 2012;104(2):147-58.

17. Prabhu A, Obi KO, Rubenstein JH. The synergistic effects of alcohol and tobacco consumption on the risk of esophageal squamous cell carcinoma: a meta-analysis. Am J Gastroenterol 2014;109(6):822-7.

18. Lam AK. Molecular biology of esophageal squamous cell carcinoma. Crit Rev Oncol Hematol 2000;33(2):71-90.

19. Parameswaran R, McNair A, Avery KN, Berrisford RG, Wajed SA, Sprangers MA, Blazeby JM. The role of health-related quality of life outcomes in clinical decision making in surgery for esophageal cancer: a systematic review. Ann Surg Oncol 2008;15(9):2372-9.
20. Berry MF. Esophageal cancer: staging system and guidelines for staging and treatment. J Thorac Dis 2014;6 Suppl 3:S289-97.

21. Stahl M, Mariette C, Haustermans K, Cervantes A, Arnold D. Oesophageal cancer: ESMO Clinical Practice Guidelines for diagnosis, treatment and follow-up. Ann Oncol 2013;24 Suppl 6:vi51-6.

22. Vega KJ, Jamal MM. Changing pattern of esophageal cancer incidence in New Mexico. Am J Gastroenterol 2000;95(9):2352-6.

23. Vega KJ, Jamal MM, Wiggins CL. Changing pattern of esophageal cancer incidence in New Mexico: a 30-year evaluation. Dig Dis Sci 2010;55(6):1622-6.

24. Hashibe M, Boffetta $P$, Janout V, Zaridze D, Shangina O, Mates D, Szeszenia-Dabrowska N, Bencko V, Brennan P. Esophageal cancer in Central and Eastern Europe: tobacco and alchohol. Int J Cancer 2007;120(7):1518-22

25. Macfarlane GJ, Boyle P. The epidemiology of oesophageal cancer in the UK and Other European countries. J R Soc Med 1994;87(6):334-7

26. Kollarova H, Machova L, Horakova D, Janoutova G, Janout V. Epidemiology of esophageal cancer an overview article. Biomed Pap Med Pac Palacky Olomouc Czech Repub 2007;151(1):17-20

27. Cancer incidence in Bulgaria, 2013. National Cancer Registry 2015(24)

28. Kotzev I, Atanasova M, Manevska B, Ivanova I, Mirchev M. Risk and protective factors for development of esophageal polyps and cancer. Bulg J Hepatogastroenterol 2007;9(1):27-33 